TOMASZ GMEREK

Uniwersytet im. Adama Mickiewicza

w Poznaniu

\title{
EDUKACJA TUBYLCZA \\ A PROCESY REWITALIZACJI ETNICZNEJ \\ AUTOCHTONICZNYCH MNIEJSZOŚCI \\ - WYBRANE MODELE I EGZEMPLIFIKACJE
}

\begin{abstract}
Gmerek Tomasz, Edukacja tubylcza a procesy rewitalizacji etnicznej autochtonicznych mniejszości - wybrane modele i egzemplifikacje [Indigenous Education and Processes of Autochtonous Minorities Ethnic Revitalization - Selected Models and Exemplifications]. Studia Edukacyjne nr 42, 2016, Poznań 2016, pp. 97-118. Adam Mickiewicz University Press. ISSN 1233-6688. DOI: 10.14746/ se.2016.42.6

The article deals with the issue of the relation between indigenous education and mainstream schooling in processes of autochtonous minorities ethnic revitalization. Particular emphasis was placed on reconstructing educational practices of indigenous schooling that is implemented toward indigenous minorities. An attempt was made at examining selected models of indigenous education concerning the relationship between schooling, language policy, teachers education and revitalization and development of languages, cultures, traditions and ethnic identity in contemporary multicultural societies.
\end{abstract}

Key words: education, autochtonous minorities, indigenous schooling, ethnic revitalisation, multicultural society, teacher education, language development

W związku z tym, iż tubylcze szkolnictwo kwestionuje wiele sposobów funkcjonowania tradycyjnego, państwowego systemu edukacji, powstaje zagadnienie sposobów jego funkcjonowania i efektów działania1. Ciekawe pytanie stawiają w tym kontekście K.A. Riley, I. Abu-Saad i M. Hermes: Czy mniejszości tubylcze powinny mieć prawo do posiadania własnego systemu

1 Niniejszy artykuł stanowi logiczną kontynuację tekstu Edukacja tubylcza a szkolnictwo głównego nurtu - konteksty teoretyczne, opublikowanego w poprzednim, 41 tomie Studiów Edukacyjnych. 
edukacji bez odniesienia do standardów narodowych?2 Autorzy - podejmujący analizę w odniesieniu do tytułowej kwestii - nie twierdzą, iż prawo mniejszości do organizacji własnego systemu szkolnictwa oznacza jego całkowite oderwanie od narodowego systemu edukacji. Twierdzą raczej, iż mniejszości mają prawo do ochrony własnej kultury i włączenia jej w główny nurt szkolnictwa ${ }^{3}$.

Generalna odpowiedź na postawione $w$ tytule artykułu pytanie nie jest prosta. Nawet odpowiedź twierdząca wiąże się $\mathrm{z}$ określonymi trudnymi konsekwencjami dla tradycyjnych autochtonicznych społeczności. Jedną z nich może być marginalizacja (pomimo uzyskanej niezależności). Warto $\mathrm{w}$ tym kontekście przeanalizować wybrane aspekty funkcjonowania tubylczej edukacji.

R.H. Heber zwraca uwagę na trzy główne modele, w których może funkcjonować edukacja tubylczych społeczności: model kolonialny, model tubylczy oraz model dwukulturowy. Pierwszy odnosi się do sytuacji edukacyjnej, w której funkcjonowało większość autochtonicznych społeczności na całym świecie. Jego istotą jest alienacja reprezentantów poszczególnych mniejszości od tubylczej kultury, tradycji i sposobów życia, w celu ich asymilacji w kulturę głównego nurtu (przez społeczeństwa dominujące).

Drugi model odnosi się do wykorzystania edukacji jako sposobu na zamknięcie kulturowe autochtonicznych społeczności, ich izolacji od kultury społeczeństwa głównego nurtu, w celu jej zachowania i ochrony. Skupia się on na rozwijaniu kształcenia opartego wyłącznie na perspektywie tubylczej. Rozwijanie kształcenia w tym modelu stanowi jednak (paradoksalnie) zagrożenie dla istnienia kultury tubylczej. Jest to związane z prawdopodobienstwem jej marginalizacji, a równocześnie zmniejszaniem możliwości jej rozwoju - w ramach wielokulturowego społeczeństwa. Kolejnym zagrożeniem jest izolacja członków społeczności tubylczej, co może doprowadzić do ograniczenia możliwości ich rozwoju w ramach społeczeństwa głównego nurtu.

Z kolei trzeci, dwukulturowy model edukacji tubylczej stanowi próbę połączenia perspektywy tubylczej oraz nie-tubylczej. Jego istotą jest zestawienie teorii i metod kształcenia z obu rzeczywistości oraz próba ich powiązania. Taki sposób organizacji edukacji tubylczej, jak pisze R.W. Heber:

może być najbardziej efektywny w sferze rozwoju tożsamości etnicznej i samopostrzegania reprezentantów autochtonicznych grup - dostarczając warunków dla ich

2 K.A. Riley, I. Abu-Saad, M. Hermes, Big Change Question. Should Indigenous Minorities Have the Right to Have Their Own Education Systems, Without Reference to National Standards? Journal of Educational Change, 2005, 6, 2, s. 177.

${ }^{3}$ Tamże, s. 178. 
społecznej i kulturowej emancypacji, a jednocześnie przygotowując do uczestnictwa we współczesnym świecie.

Jednym z istotnych aspektów organizacji szkolnictwa dla autochtonicznych grup etnicznych jest oparcie kształcenia na wiedzy tubylczej. Oznacza to zastosowanie wiedzy tubylczej w programach kształcenia, zarówno na poziomie szkolnictwa podstawowego i średniego, ale również na poziomie edukacji wyższej. Ponadto, wskazuje się coraz częściej na potrzebę włączania wiedzy tubylczej w nurt myślenia naukowego.

Historyczne tendencje świata nauki związane były z deprecjonującym ocenianiem wiedzy wywodzącej się z tradycji plemiennej i wartościującym bardzo nisko wiedzę tubylczą. Także współcześnie, relatywnie niewiele inicjatyw zmierza do włączania wiedzy tubylczej w programy kształcenia ${ }^{5}$, czy traktowania wiedzy tubylczej na poziomie równym $z$ wiedzą akademicką ${ }^{6}$. W swoich analizach I. Krupnik wskazuje na niewielkie zaawansowanie w relacjach pomiędzy wiedzą akademicką zorientowaną na wartości Zachodu a tradycyjną wiedzą tubylczą. Badania dotyczące definiowania tubylczej wiedzy w sposób pozwalający na jej integrację ze sposobami myślenia naukowego ukazują jednak $\mathrm{w}$ większym stopniu problemy dotyczące komunikacji (pomiędzy naukowcami reprezentującymi dziedziny akademickie a reprezentantami tubylczych społeczności), niż dysonans poznawczy dotyczący badanych problemów - z perspektywy naukowej i tubylczej7. Problemy komplementarności wiedzy tubylczej i wiedzy naukowej powiązane są również z interpretacją pola problemowego określonych subdyscyplin wiedzy czy „wycinków” rzeczywistości. Przykładem może być choćby interpretacja wiedzy historycznej i próby definiowania "prawdziwej”, „obiektywnej" wersji historii ${ }^{8}$. Jej kształt wygląda zupełnie inaczej $\mathrm{w}$ interpretacji historyków świata "zachodniego" niż z perspektywy tubylczej9.

${ }^{4}$ R.W. Heber, Models for Indigenous Education, [w:] Indigenous Education and International Academic Exchange, red. R.W. Heber, X. Peng, Winnipeg 2014, s. 29-31.

5 B. Collignon, Knowing Places: The Inuinnait, Landscapes and the Environment, Edmonton 2006, s. 201.

${ }^{6}$ P. Trzciński, Konstruowanie wspótczesnej tubylczości - tubylczość jako ideologia i obiekt prawa, [w:] Pierwsze narody. Społeczności rdzenne i idea tubylczości we wspótczesnym świecie, red. J. Derlicki, W. Lipiński, Warszawa 2002, s. 46.

7 I. Krupnik, Shifting Patterns, Lasting Partnerships. Inuit Knowledge and Academic Science in Arctic Cultural Research, [w:] 11th Inuit Studies Conference, red. C. Andreasen, K. Langgård, Nuuk 1998, s. 68-71.

${ }^{8}$ Y. Csonka, Changing Inuit Historicities in West Greenland and Nunavut, History and Anthropology, 2005, 16, 3, s. 321-324.

9 M. Thornton, Aspects of the History of Aboriginal People in their Relationships with Colonial, National and Provincial Governments in Canada, [w:] Aboriginal People and Other Canadians. Shaping New Relationships, red. M. Thornton, R. Todd, Ottawa 2001, s. 8. 


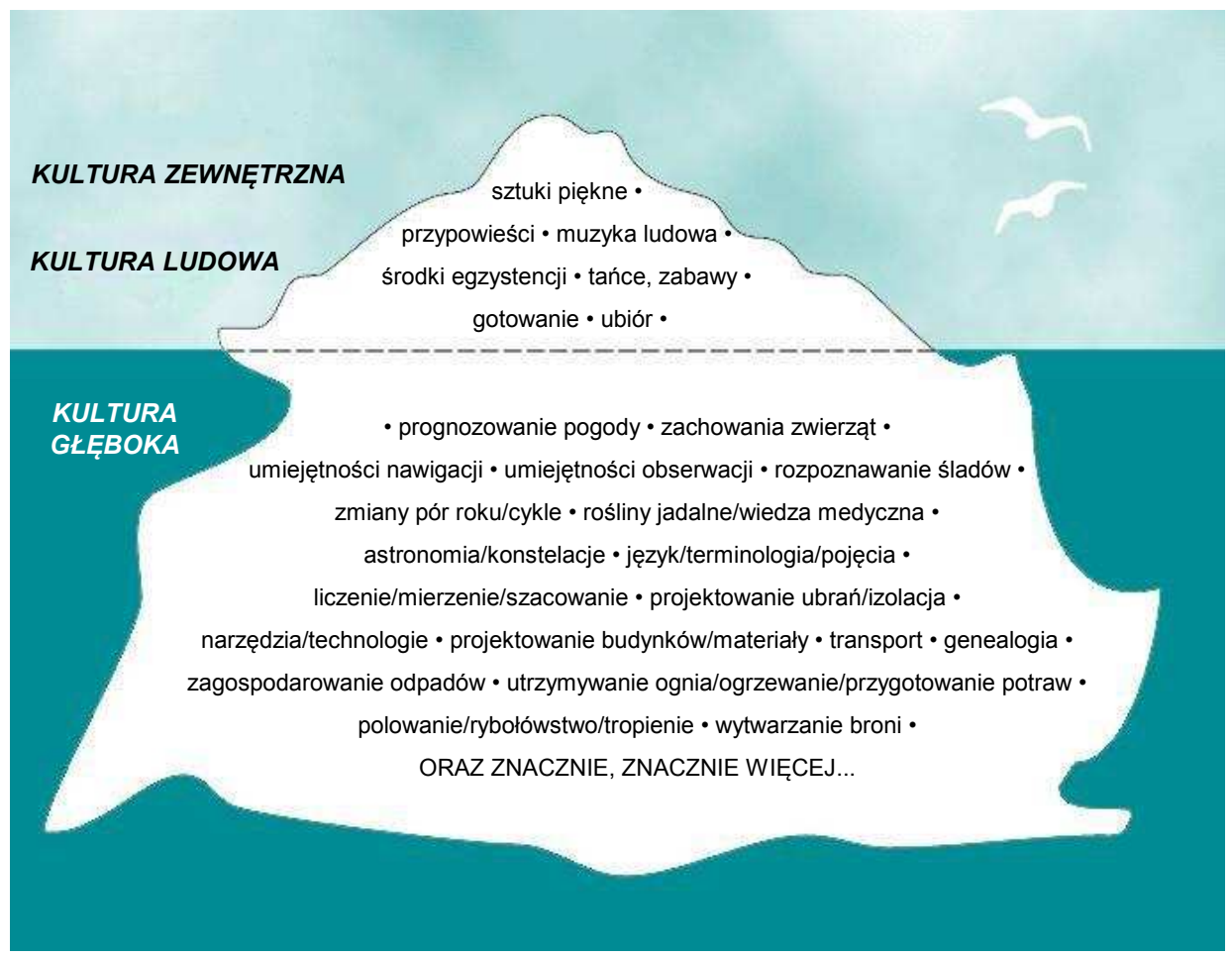

Ryc. 1. Metaforyczne przedstawienie odmiennych podejść do wiedzy i kultury tubylczej

(Źrodło: R. Barnhardt, Introduction, [w:] Sharing Our Pathways. Native Perspectives on Education in Alaska, red. R. Barnhardt, A.O. Kawagley, Fairbanks 2011, s. XV)

Współcześnie coraz częściej postuluje się jednak włączanie zasobu tradycyjnej wiedzy tubylczej do kanonu wiedzy akademickiej. Przykładem takich rozwiązań jest zastosowanie tradycyjnej wiedzy środowiskowej Inuitów, ich wiedzy tubylczej oraz tradycyjnej wiedzy akademickiej $\mathrm{w}$ poszukiwaniu rozwiązań środowiskowych i proekologicznych ${ }^{10}$. Obecne są również próby włączania tej wiedzy w programy kształcenia na poziomie szkolnictwa podstawowego i średniego ${ }^{11}$. W rzeczywistości bowiem tubylcze ludy od tysięcy lat rozwijały wiedzę i umiejętności powiązane z metodami uważnej obser-

10 F.J. Tester, P. Irniq, Inuit Qaujimajatuqangit: Social History, Politics and the Practice of Resistance, Arctic, 2008, 61, suplement 1, s. 48 i n. oraz T.K. Vlassova, Arctic Residents' Observations and Human Impact Assessments in Understanding Environmental Changes in Boreal Forests: Russian Experience and Circumpolar Perspectives, Migration and Adaptation Strategies for Global Change, 2006, 11, 4, s. 897-908.

${ }^{11}$ H.A. McGregor, Inuit. Education and Schools in the Eastern Arctic, Vancouver 2010, s. 31-34. 
wacji i badania, a także sposobów przetrwania w zróżnicowanych ekosystemach. $W$ tym czasie następowało systematyczne przystosowanie się do środowiska, wraz z wykorzystaniem jego dóbr i znajomości procesów oraz cykli przyrodniczych (w zakresie takich współczesnych sfer wiedzy, jak choćby biologia, chemia, geografia, fizyka i matematyka - ze szczególnym uwzględnieniem poszczególnych subdyscyplin wiedzy, takich jak botanika, geologia, hydrologia, meteorologia, astronomia, fizjologia, anatomia, farmakologia, technologia, inżynieria, ekologia, topografia, ornitologia, rybołówstwo, a także inne nauki stosowane). Trzeba w tym kontekście stwierdzić, iż trywializowanie wiedzy tubylczej i sprowadzanie jej wyłącznie do zwyczajów i folkloru stanowi dowód ignorancji, imperializmu i braku poszanowania dla kultury odmiennych grup etnicznych. Powierzchowne traktowanie wiedzy tubylczej związane jest z podejściem zachodniego świata nauki, powiązanym z koncepcjami nadrzędności kulturowej. Odrzucenie takiego podejścia jest warunkiem włączenia wiedzy tubylczej w nurt naukowego myślenia - na równych zasadach. Istnieje wiele obszarów, w których możliwa jest taka koegzystencja (wybrane $\mathrm{z}$ nich przedstawia ryc. 1). W metaforze lodowca zobrazowano ponadto odmienne podejścia do wiedzy i kultury tubylczej (powierzchowne, zorientowane na folklor oraz głębokie).

Także porównanie cech wiedzy tradycyjnej (tubylczej) oraz wiedzy tworzonej przez kulturę Zachodu wskazuje na istnienie wspólnego rdzenia obu tych sposobów myślenia (por. ryc. 2) ${ }^{12}$. Zróżnicowane są jedynie sposoby dochodzenia do wiedzy, jak również cele, w jakich jest ona stosowana. Istotny obszar różnic pomiędzy wiedzą tubylczą i tą wytwarzaną z perspektywy kultury "zachodniej” stanowi kontekst sytuacyjny oraz odniesienie do wartości społecznych. Odmienne są także formy przekazu i rozpowszechniania wiedzy ${ }^{13}$.

Inicjatywy podejmowane przez reprezentantów społeczności tubylczych zmierzają do powiązania różnych nurtów wiedzy w jedną całość - respektującą tubylcze formy myślenia, odczuwania i bycia. Takim celom służą na przykład inicjatywy podejmowane na Alasce, powiązane z działalnością Sieci Wiedzy Tubylczej Alaski [Alaska Native Knowledge Network] ${ }^{14}$.

12 R. Barnhardt, A.O. Kawagley, Indigenous Knowledge Systems and Alaska Native Ways of Knowing, Anthropology and Education Quarterly, 2005, 36, 1, s. 10-13.

${ }^{13} \mathrm{~J}$. Lipka, Introduction: A Framework for Understanding the Possibilities of a Yup'ik Teacher Group, [w:] Transforming the Culture of Schools. Yup'ik Eskimo Examples, red. J. Lipka, G.V. Mohatt, London 1998, s. 4-7.

${ }^{14}$ Por. Alaska Native Knowledge Network, adres internetowy: http://www.ankn.uaf.edu/ 


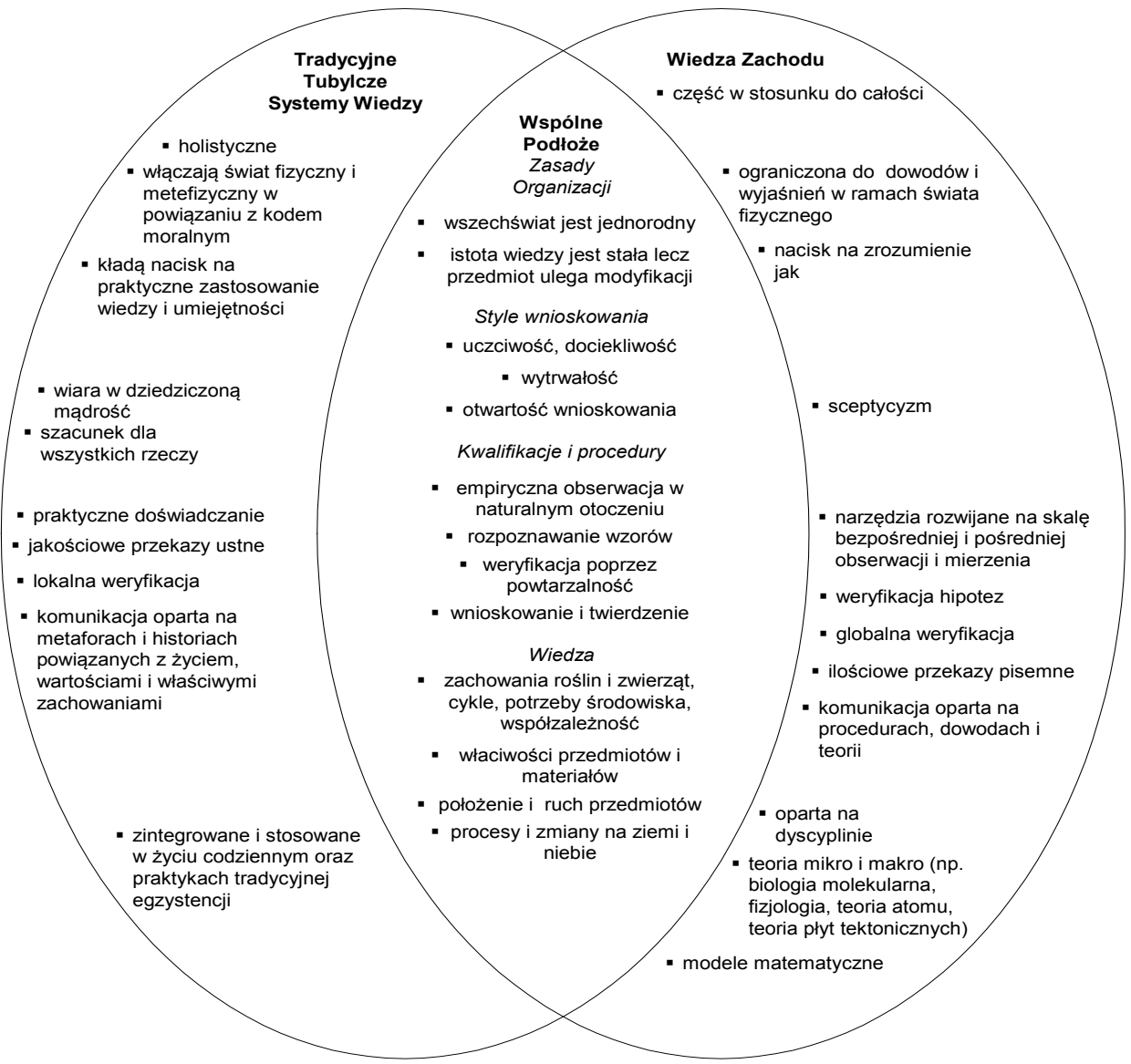

Ryc. 2. Porównanie cech wiedzy tradycyjnej (tubylczej) oraz cech wiedzy w kulturze Zachodu

(Źródło: R. Barnhardt, A.O. Kawagley, Indigenous Knowledge Systems and Alaska Native Ways of Knowing, Anthropology and Education Quarterly, 2005, 36, 1, s. 16)

J. Green zwraca w tym kontekście uwagę na konieczność uzupełnienia „kanonu” wiedzy akademickiej o treści tubylcze. Autor - analizując sytuację w Kanadzie - stawia tę tezę zarówno w odniesieniu do tendencji i przedmiotów wykładanych na kierunkach typowo tubylczych, jak i wchodzących w skład regularnych kursów studiów ${ }^{15}$. Trzeba przy tym stwierdzić, że choć studia tubylcze [Native studies] stanowią w Kanadzie odrębną dyscyplinę

15 J. Green, Cannon Fodder: Examining the Future of Native Studies, [w:] Pushing the Margins: Native and Northern Studies, red. J. Oakes, R. Riewe, M. Bennett, B. Chisholm, Winnipeg 2001, s. $42-43$ i n. 
wiedzy, wykładaną na większości uniwersytetów, to jednak równocześnie jak stwierdza J. Green - „pozostają marginalizowane zarówno jeśli chodzi o bazę materialną, jak i kontekst ich funkcjonowania". Zauważalna tendencja marginalizacji kierunków tubylczych ze strony "tradycyjnych" wydziałów związana jest między innymi ze specyfiką ich pozycji w ramach Akademii. Odnosi się to przede wszystkim do ich opozycji względem dominujących ideologii, tworzenia nowych (tubylczych) koncepcji naukowych - tworzonych przez reprezentantów autochtonicznych społeczności, odejścia od akademickiego kanonu wiedzy, sposobów funkcjonowania studentów pochodzących ze społeczności tubylczych, konkurencji o fundusze $\mathrm{w}$ ramach uczelni itd. $\mathrm{W}$ sferze funkcjonowania studiów tubylczych pojawiają się więc wyraźne sprzeczności, a nawet konflikt interesów, zarówno pod względem naukowym jak i społecznym ${ }^{16}$.

Sprzeczności w sferze studiów tubylczych dotyczą także roli edukacji $\mathrm{w}$ procesie kształcenia studentów, zarówno tubylczych jak i nie-tubylczych (także w roli przyszłych nauczycieli). Inne sprzeczności i kontrowersje dotyczą konstruowania programów kształcenia ${ }^{17}$. Dla przedstawicieli autochtonicznych mniejszości etnicznych istotne są $\mathrm{w}$ tym przypadku wizje i cele, jakie stawiają sobie twórcy modeli kształcenia w lokalnych tubylczych społecznościach ${ }^{18}$.

Doświadczenia tubylczej edukacji nie dotyczą jednak wyłącznie tubylczych społeczności. Kierowane są one bowiem także do reprezentantów innych grup etnicznych, w tym i uczniów reprezentujących kulturę dominującą. W tym kontekście celem staje się integracja treści tubylczych w szkołach reprezentujących główny nurt kształcenia. Y. Kanu opisuje inicjatywę włączenia elementów wiedzy i kultury tubylczej w program kształcenia przeznczony dla klas mieszanych (złożonych z uczniów reprezentujących mniejszości rdzenne, jak też innych) w kilku szkołach średnich na terytorium prowincji Manitoba - w Kanadzie. Podjęte działania ogniskowały się na pięciu poziomach funkcjonowania edukacji szkolnej: 1) planowania scenariusza lekcji, kiedy tworzone są cele kształcenia; 2) zawartości programu i materiałów kształcenia; 3) metod i strategii kształcenia; 4) planowanych

16 Tamże, s. 41.

${ }_{17}$ M.L. Jennings, J.R. Collier, One University, Two Universes: Alaska Natives and the University of Alaska-Anchorage, [w:] Native American Studies in Higher Education. Models for Collaboration between Universities and Indigenous Nations, red. D. Champagne, J. Strauss, Walnut Creek 2002, s. 221-225.

18 S. Watt-Cloutier, Honouring Our Past, Creating Our Future: Education in Northern and Remote Communities, [w:] Aboriginal Education. Fulfilling the Promise, red. M.B. Castellano, L. Davis, L. Lahache, Vancouver 2000, s. 115-127. 
rezultatów kształcenia; 5) osadzenia programu w określonej filozofii kształcenia $^{19}$.

Tabela 1

Przykładowe tubylcze treści włączone w przedmioty w ramach programu kształcenia w wybranych szkołach średnich prowincji Manitoba

\begin{tabular}{|c|c|}
\hline Przedmiot & $\begin{array}{l}\text { Cele wprowadzenia tubylczych treści do programu kształcenia } \\
\text { jako zadania do realizacji przez uczniów w wybranych szkołach. } \\
\text { Uczniowie będą: }\end{array}$ \\
\hline $\begin{array}{l}\text { Język } \\
\text { angielski }\end{array}$ & $\begin{array}{l}\text { - znać sposób rozumienia znaczenia tradycji ustnego przekazu } \\
\text { w tubylczych kulturach } \\
\text { - pokazywać sposób rozumienia zasad związanych z tubylczą ustną } \\
\text { tradycją (np. słuchaniem, okazywaniem szacunku osobie przema- } \\
\text { wiającej, zachowania właściwego okresu roku na opowiadanie po- } \\
\text { szczególnych historii itd.) } \\
\text { - analizować wybrane książki/teksty w celu ukazania i zrozumienia } \\
\text { społecznych, kulturowych i politycznych problemów dotyczących } \\
\text { ludów tubylczych zobrazowanych w książkach i tekstach (np. rasi- } \\
\text { zmu, stereotypów, roszczeń prawa do ziemi, zdrowia i stylów życia) } \\
\text { - dokonywać ewaluacji poprawności sposobów prezentowania lu- } \\
\text { dów tubylczych w różnych mediach }\end{array}$ \\
\hline Matematyka & $\begin{array}{l}\text { - charakteryzować sposoby użycia geometrii w tradycyjnych kultu- } \\
\text { rach tubylczych } \\
\text { - posiadać znajomość tradycyjnych technik mierzenia i liczenia } \\
\text { w świadomości ludów tubylczych } \\
\text { - poznawać przykłady koncepcji analogii, równowagi i symetrii } \\
\text { w tubylczej sztuce i architekturze }\end{array}$ \\
\hline Muzyka & $\begin{array}{l}\text { - opisywać rolę tradycyjnej muzyki w społecznościach tubylczych } \\
\text { - identyfikować tradycyjną muzykę autochtonicznych grup } \\
\text { - pokazywać świadomość zasad związanych z odtwarzaniem trady- } \\
\text { cyjnych pieśni } \\
\text { - posiadać świadomość wkładu reprezentantów tubylczych społecz- } \\
\text { ności we współczesny przemysł muzyczny }\end{array}$ \\
\hline Nauki ścisłe & $\begin{array}{l}\text { - posiadać świadomość wkładu autochtonicznych społeczeństw } \\
\text { w rozwój nauk ścisłych i technicznych } \\
\text { - pokazywać sposoby rozumienia zasad fizyki zastosowanych } \\
\text { w różnych tubylczych technologiach } \\
\text { - rozumieć i doceniać wartość tradycyjnej wiedzy tubylczej odnoszą- } \\
\text { cej się do ziemi, roślin oraz zmian w ekosystemach } \\
\text { - pokazywać przykłady zastosowania tradycyjnej medycyny używa- } \\
\text { nej przez ludy tubylcze }\end{array}$ \\
\hline Sztuka & $\begin{array}{l}\text { - rozumieć różne typy sztuki tubylczej oraz ich pochodzenie } \\
\text { - opisywać odmienne aspekty pracy tubylczych artystów (np. tema- } \\
\text { ty, style, elementy tradycyjnego wzornictwa) }\end{array}$ \\
\hline
\end{tabular}

19 Y. Kanu, Integrating Aboriginal Perspectives Into the School Curriculum: Purposes, Possibilities, and Challenges, Toronto 2011, s. 95. 


\begin{tabular}{|l|l|}
\hline \multicolumn{1}{|c|}{ Przedmiot } & \multicolumn{1}{|c|}{$\begin{array}{c}\text { Cele wprowadzenia tubylczych treści do programu kształcenia } \\
\text { jako zadania do realizacji przez uczniów w wybranych szkołach. } \\
\text { Uczniowie będą: }\end{array}$} \\
\hline Sztuka & $\begin{array}{l}\text { - analizować podobieństwa i różnice w pracy współczesnych tubyl- } \\
\text { czych artystów }\end{array}$ \\
\hline Edukacja & $\begin{array}{l}\text { - posiadać znajomość i uczestniczyć w tradycyjnych tubylczych } \\
\text { grach i tańcach }\end{array}$ \\
fizyczna & $\begin{array}{l}\text { - identyfikować tubylcze modele ról w różnych sportach } \\
\text { - posiadać znajomość korzyści zdrowotnych płynących z aktywności } \\
\text { fizycznej } \\
\text { - dokonywać ewaluacji sposobów użycia obrazu tubylców w sporcie }\end{array}$ \\
\hline
\end{tabular}

Źródło: opracowanie własne na podstawie Y. Kanu, Integrating Aboriginal Perspectives Into the School Curriculum: Purposes, Possibilities, and Challenges, Toronto 2011, s. 107-109.

W tabeli 1 przedstawione są przykładowe kwestie, jakie podejmowane były $\mathrm{w}$ ramach eksperymentu służącego integracji wiedzy tubylczej w główny nurt kształcenia - na poziomie szkoły średniej. Obejmują one szeroki zestaw treści dotyczących funkcjonowania tubylczych społeczności w Kanadzie. Widać wyraźnie, iż możliwości wprowadzenia elementów tubylczych oraz ich zastosowania praktycznego istnieją w każdym przedmiocie. Równocześnie, jak stwierdza Y. Kanu:

trzeba pamiętać, iż te rozwiązania i cele, jak i inne tubylcze perspektywy w edukacji nie powinny być traktowane jako dodatek czy rozszerzenie "głównego programu". Muszą one posiadać swoje uprawomocnione miejsce w centrum programu kształcenia, wraz z innymi typowo definiowanymi celami kształcenia ${ }^{20}$.

Zwykle jednak, tubylcza edukacja tworzona jest przede wszystkim dla reprezentantów autochtonicznych społeczności. D. Taylor, M. Crago i L. McAlpine zwracają uwagę na dwie istotne kwestie przy definiowaniu programów kształcenia w szkolnictwie dla mniejszości tubylczych: Czego oczekuje lokalna społeczność od formalnej edukacji wobec własnych dzieci?; Co powinni wiedzieć absolwenci, jak powinni się czuć i co powinni umieć zrobić? W tym kontekście powinny zostać dostarczone możliwości zmiany w programach kształcenia - możliwe do przeprowadzenia na poziomie lokalnych społeczności - i odpowiadające na ich konkretne potrzeby ${ }^{21}$.

Tego typu oczekiwania mają odmienną logikę i cele, a często stają wręcz w sprzeczności z narodowymi programami kształcenia. Ilustracją tego zjawiska mogą być choćby cele kształcenia i wychowania obecne w tubylczym

20 Tamże, s. 109.

${ }^{21}$ D.M. Taylor, M.B. Crago, L. McAlpine, Toward Full Empowerment in Native Education: Unanticipated Challenges, The Canadian Journal of Native Studies, 2001, 21, 1, s. 47. 
programie kształcenia szkoły średniej funkcjonującej w społeczności Indian Nawahów w stanie Nowy Meksyk - w Stanach Zjednoczonych (por. tabela 2). Jak bowiem zauważa K. Manuelito,

kategorie i subkategorie edukacji Nawaho są niekompatybilne z euro-amerykańskim podziałem wiedzy na przedmioty takie jak matematyka, nauki ścisłe, nauki społeczne czy nauczanie języka. Jednak użycie ich w sferze reprezentacji lokalnej wiedzy wymaga zarówno od tubylczych, jak i nie-tubylczych nauczycieli uczenia się od społeczności. [Równocześnie], powiązanie pomiędzy właściwą edukacją i samostanowieniem jest oczywiste dla społeczności Nawahów. Edukacja - podtrzymująca samoświadomość [ádééhólzin] - stanowi kluczowy, żywy aspekt samostanowienia22.

Tabela 2

Dziedziny i elementy formujące wykształconą osobę w epistemologii Indian Nawaho

\begin{tabular}{|c|c|}
\hline Dziedzina & Elementy \\
\hline Mądrość przodków & $\begin{array}{l}\text { K'é [szacunek, system pokrewieństwa] } \\
\text { Wiedza dotycząca pochodzenia klanowego jednostki (ze strony } \\
\quad \text { ojca i matki) } \\
\text { Wiedza dotycząca relacji pomiędzy klanami } \\
\text { Wiedza dotycząca historii klanu, z którego wywodzi się jed- } \\
\quad \text { nostka } \\
\text { Wiedza dotycząca odpowiedzialności klanowej/systemu po- } \\
\quad \text { krewieństwa }\end{array}$ \\
\hline $\begin{array}{l}\text { Nauczanie } \\
\text { przodków }\end{array}$ & $\begin{array}{l}\text { Historia } \\
\text { Wiedza dotycząca własnej rodziny } \\
\text { Wiedza dotycząca własnej społeczności } \\
\text { Wiedza dotycząca plemienia Nawahów } \\
\text { Środowisko } \\
\text { Wiedza dotycząca konstelacji } \\
\text { Wiedza dotycząca pór roku, faz księżyca i kalendarza } \\
\text { Wiedza dotycząca warunków pogodowych, znaków i wpływów } \\
\text { Wiedza dotycząca gospodarowania i zielarstwa } \\
\text { Wiedza dotycząca wypasu zwierząt } \\
\text { Wiedza dotycząca zimowych przypowieści } \\
\text { Wiedza dotycząca pieśni używanych przez społeczność } \\
\text { Wiedza dotycząca umiejętności i przypowieści myśliwskich } \\
\text { Wiedza dotycząca przygotowania posiłków (dań z kukurydzy, } \\
\text { pożywienia zimowego) } \\
\text { Wiedza dotycząca obróbki mięsa wraz z powiązanymi przypo- } \\
\text { wieściami }\end{array}$ \\
\hline
\end{tabular}

${ }^{22} \mathrm{~K}$. Manuelito, The Role of Education in American Indian Self-Determination: Lessons from Ramah Navajo Community School, Anthropology and Education Quarterly, 2005, 36, 1, s. 83. 


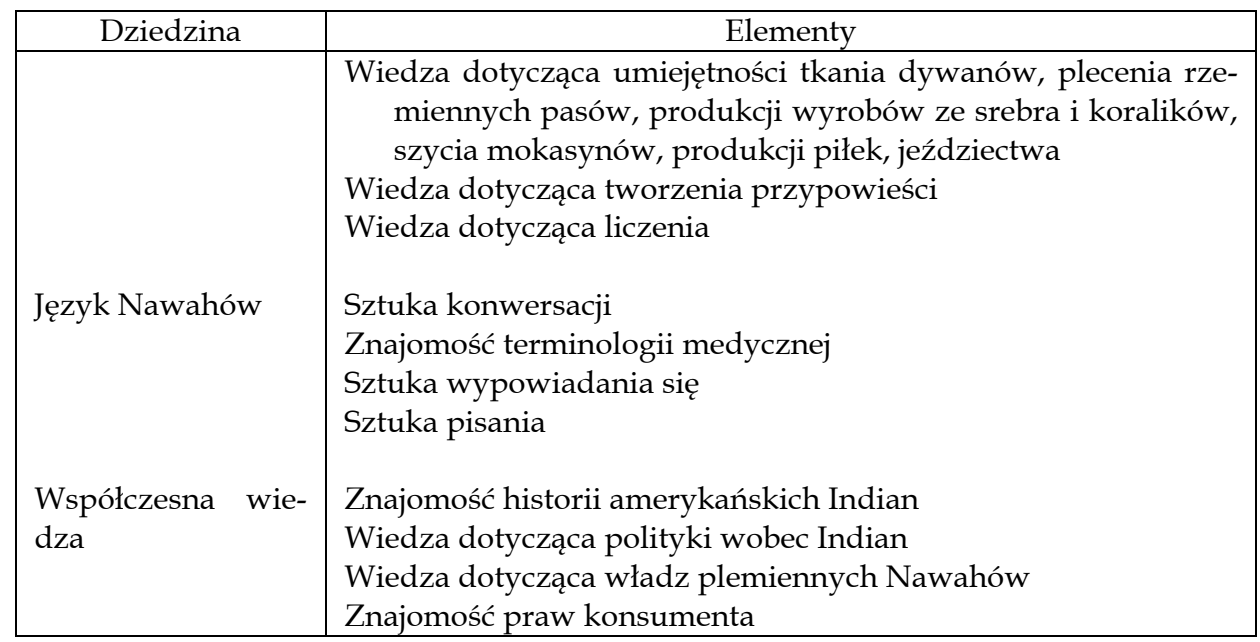

Źródło: K. Manuelito, The Role of Education in American Indian Self-Determination: Lessons from Ramah Navajo Community School, Anthropology and Education Quarterly, 2005, 36, 1, s. 83.

Jeden z najważniejszych aspektów dotyczących funkcjonowania tubylczej edukacji związany jest - jak już o tym wspomniano - ze sposobami kształcenia nauczycieli. Choć istnieje znaczna liczba rozwiązań w sferze przygotowania kadry pedagogicznej i dydaktycznej do pracy z reprezentantami autochtonicznych mniejszości, to jednak można zauważyć dwie główne (i opozycyjne) strategie, pomiędzy którymi zawierają się poszczególne rozwiązania.

Pierwszą strategią kształcenia nauczycieli jest główny nurt edukacji akademickiej. Odbywa się ona w kampusach uniwersyteckich, do których zgłaszają się reprezentanci grup etnicznych. Ich podania mogą być rozpatrywane na warunkach podobnych, jakie mają pozostali studenci; mogą być także zastosowane formy działań afirmatywnych. Kiedy reprezentant mniejszości zostanie przyjęty na studia, kształci się $\mathrm{w}$ takim samym trybie i zakresie materiału, jak pozostali studenci. Oznacza to, iż w programie kształcenia nie ma elementów dotyczących wiedzy tubylczej. W niektórych przypadkach istnieje możliwość połączenia zwykłego programu kształcenia z dodatkowymi elementami wiedzy tubylczej lub wyboru dodatkowych przedmiotów z programu studiów tubylczych [Native studies].

Drugą - i opozycyjną wobec pierwszej - strategią kształcenia nauczycieli jest oderwanie od głównego nurtu edukacji akademickiej. Wybierają ją społeczności pragnące własnej kontroli nad kształceniem nauczycieli. Zdarza się, że rezygnują z akredytacji dla uczelni, aby zachować wolność od ze- 
wnętrznych zaleceń władz oświatowych. Celem jest w tym przypadku chęć silnej orientacji programu kształcenia na języku i kulturze mniejszości23.

Generalnie można postawić tezę, że im bardziej kształcenie oparte jest na tubylczym dziedzictwie kulturowym, tym bardziej staje się odległe od kształcenia w głównym nurcie. Modele edukacji tubylczej włączają bowiem wiele tradycyjnych elementów z życia lokalnych społeczności w program nauczania ${ }^{24}$. Jest to zrozumiałe, zważywszy że rolą tak rozumianej edukacji jest przekaz treści i wartości kultury tubylczej, a także związanych z nią kompetencji społecznych. W tym kontekście, rolą nauczyciela staje się osadzenie procesu kształcenia $\mathrm{w}$ lokalnej społeczności, wraz $\mathrm{z}$ odwołaniem się do jej doświadczeń, wiedzy i sposobów funkcjonowania. Jest to zupełnie odmienne postrzeganie roli nauczyciela i kierunków jego działania, które redefiniuje znacząco jego rolę. Przykład tego sposobu postrzegania celów działania nauczycieli ilustruje przykład tubylczej edukacji w Kanadzie w społeczności Inuitów w Nunavik (por. ryc. 3).

A. Konwencjonalna rola nauczyciela

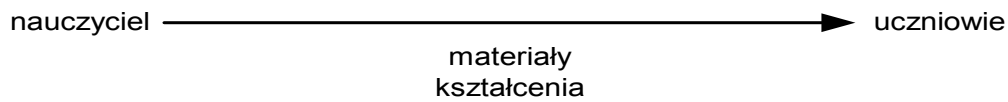

B. Rola tubylczego nauczyciela (Model Kativik)

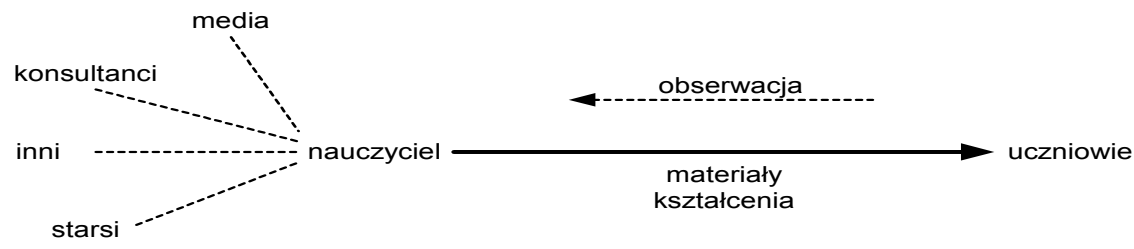

Ryc. 3. Rola nauczyciela w szkolnictwie tradycyjnym i tubylczym

(Źródło: A. Stairs, Beyond cultural inclusion. An Inuit example of indigenous educational development, [w:] Minority Education: From Shame to Struggle, red. T. Skutnabb-Kangas, J. Cummins, Philadelphia 1998, s. 318) s. 48 .

${ }^{23}$ D.M. Taylor, M.B. Crago, L. McAlpine, Toward Full Empowerment in Native Education,

${ }^{24}$ D. Champagne, J. Stauss, Defining Indian Studies through Stories and Nation Building, [w:] Native American Studies, s. 3-11. 
Członkowie tubylczych społeczności poszukują najczęściej osób z kompetencjami odnoszącymi się do przekazu tradycyjnej wiedzy i umiejętności, nawet kosztem wiedzy opartej na kulturze zachodniej. W związku z tym, iż znajomość języka określonej społeczności stanowi kluczowy element (re)konstruowania tożsamości etnicznej najmłodszych jej członków, jest to również ważne kryterium $\mathrm{w}$ rekrutacji tubylczych nauczycieli. Także takie umiejętności ważne z perspektywy kultury tubylczej, jak sztuka polowania, łowienia, czy sztuka przeżycia $\mathrm{w}$ arktycznym środowisku wyznaczają kryteria dobrego nauczyciela. $Z$ kolei, kompetencje tak wybranego nauczyciela (także jako nauczyciela akademickiego) - wartościowane $\mathrm{z}$ perspektywy kształcenia akademickiego głównego nurtu - mogą wydawać się niskie i niewystarczające. Rodzi to określone problemy w sposobach funkcjonowania tubylczego szkolnictwa ${ }^{25}$.

W tym kontekście istnieje wiele zmiennych wpływających na ostateczny kształt funkcjonowania zawodu nauczyciela $\mathrm{w}$ szkolnictwie $\mathrm{w}$ lokalnych społecznościach. Jednym $\mathrm{z}$ nich jest coraz to większa trudność w znajdowaniu odpowiednich nauczycieli (o określonych "tradycyjnych" kompetencjach). Inny czynnik związany jest z oczekiwaniami rodziców z autochtonicznych społeczności, którzy, paradoksalnie, często nie chcą definitywnej orientacji edukacji na kulturę tubylczą (dotyczy to przede wszystkim obaw wyrażanych przez rodziców, że ich dzieci nie poradzą sobie w rzeczywistości społecznej nie posiadając kompetencji związanych z kulturą zachodnią). Ten czynnik także przekształca oczekiwania względem tubylczych nauczycieli w zakresie posiadania przez nich znaczących kompetencji powiązanych z kulturą głównego nurtu'26.

Warto $\mathrm{w}$ tym miejscu przybliżyć założenia jednego z modeli edukacji tubylczej, który - jak się wydaje - wpisuje się w szerokie, holistyczne rozumienie rozwoju współczesnej edukacji tubylczej. Pokazuje on, jak bardzo tubylcze programy kształcenia mogą odbiegać od regularnych „narodowych" koncepcji edukacyjnych. Dotyczy to wielu kluczowych elementów funkcjonowania szkolnictwa (takich jak język wykładowy, filozofia wychowania, promowany system wartości, rola nauczycieli, czy podejście wobec ucznia).

Model edukacji tubylczej „Podążaj do źródła” oparty jest na pięciu głównych elementach. Pierwszym z nich jest tubylczy język. Programy kształcenia przewidywane $\mathrm{z}$ perspektywy tego modelu muszą rozwijać kompetencje językowe - zarówno w zakresie pisania jak i mowy. Lokalny

${ }_{25}$ D.M. Taylor, M.B. Crago, L. McAlpine, Toward Full Empowerment in Native Education, s. $48-49$.

26 Tamże, s. 50. 
język kształtuje z tej perspektywy podstawowe związki z plemienną historią i słynnymi przodkami. Celem jest jednak rozwijanie środowiska wielojęzycznego, bowiem „realia życia w społeczności globalnej oznaczają konieczność znajomości odmiennych języków i historii".

Drugi element stanowi rozwijanie tubylczego rozumienia kultury i historii, powiązań pomiędzy przeszłością i przyszłością, a także sposobów rozumienia współczesnych wydarzeń. Oznacza to takie ujmowanie doświadczeń i wiedzy tubylczej, które odrywa się od stereotypizacji i stanowi rzeczywiste ich włączenie $\mathrm{w}$ materiały kształcenia. Istotne jest tutaj powtórne odczytanie historii z perspektywy tubylczej, mające na celu konstruowanie lokalnej obywatelskiej odpowiedzialności.

Kolejny element stanowi program kształcenia. Ma on być zorientowany na takie wartości, jak samodeterminacja, poczucie szacunku wobec własnej kultury, a także osobistej wizji i zaangażowania. Cytowani autorzy stwierdzają, że

punktem wyjścia są $\mathrm{w}$ tym przypadku, podobnie jak $\mathrm{w}$ celu drugim, doświadczenia wyniesione $\mathrm{z}$ instytucji edukacyjnych, które marginalizowały sposoby bycia i myślenia dzieci i młodzieży pochodzących z mniejszości tubylczych, które one przynosiły do klasy szkolnej27.

Kształcenie w modelu tubylczej edukacji musi być dla reprezentantów grup mniejszościowych „wyzwalające”.

$\mathrm{Z}$ takim podejściem powiązany jest czwarty istotny element, jaki stanowi określony wzorzec nauczania i uczenia się. Nauczanie i uczenie się są postrzegane jako procesy budujące odpowiedzialność za siebie, rodzinę, społeczność lokalną i aktywnie włączające rodziny oraz całą tubylczą społeczność w procesy edukacyjne. Następuje tutaj odrzucenie indywidualistycznej koncepcji uczenia się na rzecz koncepcji wspólnotowej. M.K.P. Nee-Benham i J.E. Cooper tak opisują współpracę przy tworzeniu projektu:

Lekcje, które każdy z nas otrzymał na naszej indywidualnej edukacyjnej drodze i w rozmowach z innymi w czasie zebrań, spowodowały konieczność dzielenia się, wspierania i uczenia jeden od drugiego. Nauczyliśmy się, że izolacja prowadzi do idei szybkiej śmierci, a wymiana doświadczeń pomiędzy społecznościami tubylczymi prowadzi do rozwoju ${ }^{28}$.

27 Tamże.

28 M.K.P. Nee-Benham, J.E. Cooper, Gathering Together to Travel to the Source: A Vision for a Language and Culture-Based Educational Model, [w:] Indigenous Educational Models for Contemporary Practice. In Our Mother's Voice, red. M.K.P. Nee-Benham, J.E. Cooper, Mahwah 2000, s. 15. 
Wreszcie piąty element dotyczy rozwoju i promocji praktyki tubylczych programów kształcenia. Wykorzystanie ich ma na celu znaczące podniesienie wyników kształcenia, obniżenie zjawisk opuszczania szkoły i odsiewu szkolnego, a także eliminację problemów społecznych wśród dzieci i młodzieży z mniejszości tubylczych.

W rozważaniach autorzy podkreślają obawy związane $\mathrm{z}$ tworzeniem jednego modelu edukacji tubylczej - dla wszystkich autochtonicznych społeczności. Związane były one z tym, że zatraci on cechy odróżniające poszczególne grupy i nabierze charakteru "ogólno-tubylczego" [pan-Native] ${ }^{29}$. W rezultacie, reprezentanci poszczególnych społeczności zdecydowali nie konstruować jednorodnego systemu wartości dla przedstawionego programu edukacji; ograniczyli się jedynie do stworzenia kilku naczelnych zasad, w jakich powinny funkcjonować tubylcze modele oświatowe.

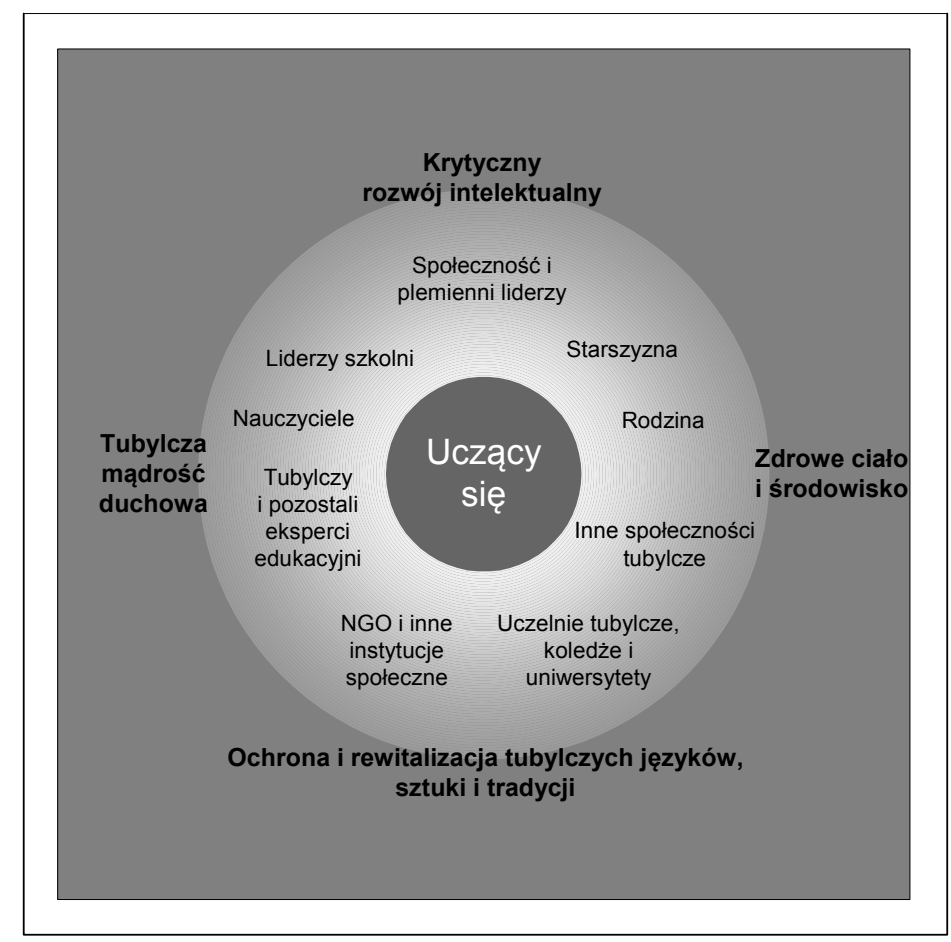

Ryc. 4. Model edukacji tubylczej „Podążaj do Źródła”

(Źródło: M.K.P. Nee-Benham, J.E. Cooper, Gathering Together to Travel to the Source: A Vision for a Language and Culture-Based Educational Model, [w:] Indigenous Educational Models for Contemporary Practice. In Our Mother's Voice, red. M.K.P. Nee-Benham, J.E. Cooper, Mahwah 2000, s. 16)

${ }^{29}$ Tamże. 
W tym kontekście wyróżniono cztery zasady myślenia o edukacji tubylczej, będące podstawą dla tworzenia konkretnych programów kształcenia uwzględniających wartości, style życia i działania poszczególnych autochtonicznych społeczności. Są one następujące:

1. Tubylcza mądrość duchowa, która jest przewodzona przez serca przodków.

2. Krytyczny rozwój myślenia, który łączy tubylcze sposoby postrzegania i działania $z$ nowoczesnymi sposobami postrzegania i działania.

3. Promowanie zdrowego ciała i zdrowego środowiska.

4. Ochrona i rewitalizacja tubylczych języków, sztuki oraz tradycji30.

Schemat odniesień takiego modelu edukacji tubylczej prezentuje rycina 4. W symboliczny sposób przedstawia on ognistą obręcz, ze słońcem $\mathrm{w}$ centrum. W centrum modelu kształcenia jest uczący się, który stanowi ogniwo łączące zarówno przeszłość, jak i przyszłość. Planowanie procesu kształcenia, jego praktyka, pedagogia, sposób zarządzania i struktura organizacyjna musi zatem wspierać uczącego się. Postuluje się osadzenie procesu kształcenia $\mathrm{w}$ czterech podstawowych składnikach życia, takich jak krytyczny rozwój intelektualny, zdrowe ciało i środowisko, ochrona języka oraz mądrość duchowa. Istotne jest także celebrowanie tubylczych uroczystości ${ }^{31}$.

Wyróżnione powyżej elementy osadzone są w specyfice funkcjonowania wiedzy, społeczności lokalnej oraz rodziny. Tubylcza edukacja powinna odnosić się do wiedzy stanowiącej dziedzictwo przeszłości pochodzące od przodków, jak też $\mathrm{w}$ zrównoważony sposób łączyć przeszłość z przyszłością. Pomocne $\mathrm{w}$ procesie nabywania wiedzy są oddziaływania wspólnoty lokalnej jako środowiska uczenia się:

edukacyjne zabiegi muszą być interdyscyplinarne, interkulturowe i angażować wszystkie pokolenia społeczności. Ponadto, przetrwanie inicjatyw edukacyjnych wymaga zaangażowania starszyzny, różnych wewnętrznych i zewnętrznych tubylczych i nie tubylczych agencji, a także powiązań z innymi tubylczymi projektami ${ }^{32}$.

Ostatnim elementem, w którym osadzone są inicjatywy oświaty tubylczej jest rodzina. To ona stanowi podstawę dla formowania tubylczej świadomości, tożsamości i wypływających z nich praktyk, a także podstawę dla rozwoju poczucia duchowości, własnego ja oraz tożsamości kulturowej. Istnieje założenie, że wszystkie instytucje muszą wspierać rodzinę w realiza-

\footnotetext{
30 Tamże, s. 16.

31 Tamże, s. 17.

32 Tamże.
} 
cji tych celów. Warto zwrócić uwagę, że schemat w kształcie okręgu symbolizuje konieczność równowagi pomiędzy wszystkimi elementami33.

Także i z tej perspektywy kluczowe dla powodzenia edukacji są odpowiednio przygotowane kadry nauczycielskie, których kompetencje, powiązane z działaniem całej społeczności, mają bowiem stanowić aktywnych lokalnych liderów. Ich zadaniem jest rozwijanie działań opartych na sposobach funkcjonowania społeczności lokalnej, także integracja dawnych i współczesnych praktyk, jak również współdziałanie z tubylczymi i nietubylczymi jednostkami oraz grupami w celu opracowania doświadczeń dla kształcenia ogólnego, rozwoju umiejętności i tradycyjnych praktyk, jak i stwarzanie możliwości włączania członków społeczności w wydarzenia związane $\mathrm{z}$ ochroną języka i kultury ${ }^{34}$. Tak podsumowują istotę działania zaprezentowanego modelu M.K.P. Nee-Benham i J.E. Cooper:

W skrócie, nasz model zmierza do budowy silnych edukacyjnych społeczności zorientowanych wokół rodziny, chroniących i rewitalizujących tubylcze języki i kultury oraz wspierających tożsamość i niezależność jednostki. Samo-uprawomocnienie edukacyjnych instytucji (np. szkół), stanowi trudną pracę, ponieważ wymaga zrównoważonych działań ze strony jednostek (uczniów, nauczycieli i dyrektorów szkolnych), a także społeczności (plemiennej, szkolnej) na rzecz uczciwego spojrzenia na przeszłość, jak również krytycznego i pragmatycznego spojrzenia na teraźniejszość i przyszłość (...) Model ten stanowi źródło, w którym pokładamy podstawy naszego zaangażowania, pasji i którego znaczenie odzwierciedla nasze tubylcze sposoby myślenia ${ }^{35}$.

Jak wspomniano, założeniem funkcjonowania tubylczej edukacji jest osadzenie procesu kształcenia w szerokim kontekście oddziaływań społeczności tubylczej. Przykładem takich rozwiązań może być choćby współczesna edukacja Samów w krajach skandynawskich. Warto w tym miejscu zwrócić uwage na rozwijany $\mathrm{w}$ Finlandii program kształcenia lapońskich dzieci i młodzieży. Jest on osadzony w ramach wartości kultury tej grupy etnicznej.

Lapońskie modele tubylczej edukacji odwołują się do tradycji, kultury i historii społeczności od tysięcy lat zamieszkujących Półwysep Skandynawski. W Finlandii jego podstawę stanowi kilka kluczowych elementów (por. ryc. 5). Usytuowane są one względem percepcji świata Samów (symbolizują je trzy poziomy, na których osadzone są poszczególne elementy). Pierwszy poziom odwołuje się do najbardziej transcendentalnych wartości, które powiązane są jednak współcześnie także z wartościami i celami działania sam-

\footnotetext{
33 Tamże, s. 18.

34 Tamże, s. 19-20.

35 Tamże, s. 20.
} 
skiej edukacji. Język lapoński usytuowany jest w centrum, co świadczy o jego kluczowym znaczeniu w edukacji tworzonej specjalnie dla reprezentantów tej tubylczej społeczności. Poniżej znajdują się elementy służące zapewnieniu warunków dla właściwej organizacji procesu kształcenia i wychowania, a także osadzenia go $\mathrm{w}$ odpowiednich ramach społecznych i kulturowych ${ }^{36}$.



Ryc. 5. Tradycyjny szamański bęben symbolizujący rozwój samskiej edukacji

(Źródło: P. Keskitalo, K. Määttä, S. Uusiautti, Sámi Education, Frankfurt 2013, s. 91)

Innym przykładem inicjatyw służących odrodzeniu języka jako głównego nośnika kultury tubylczej jest model kształcenia rozwijany od lat siedemdziesiątych XX wieku w Instytucie Rozwoju Języków Amerykańskich Indian [American Indian Language Development Institute - AILDI]. Instytut powstał w 1978 roku jako oddolna inicjatywa grupy osób reprezentujących tubylcze społeczności językowe Digueno, Havasupai, Hualapai, Mohave i Yavapai, we współpracy z lingwistami z Uniwersytetu Berkeley [Berkeley University] oraz z Uniwersytetu San Diego [San Diego State University].

${ }^{36}$ P. Keskitalo, K. Määttä, S. Uusiautti, Sámi Education, Frankfurt 2013, s. 90-93. 
Współcześnie instytut funkcjonuje na Uniwersytecie Arizona [University of Arizona], służąc znacznie większej liczbie indiańskich społeczności ${ }^{37}$.

Program rozwijany w Instytucie Rozwoju Języków Amerykańskich Indian dotyczy wzmacniania tubylczych języków i autochtonicznych kultur za pośrednictwem działań edukacyjnych kierowanych do reprezentantów społeczności Indian w Stanach Zjednoczonych. Działanie programu opiera się na czterech poziomach oddziaływań (por. ryc. 6).

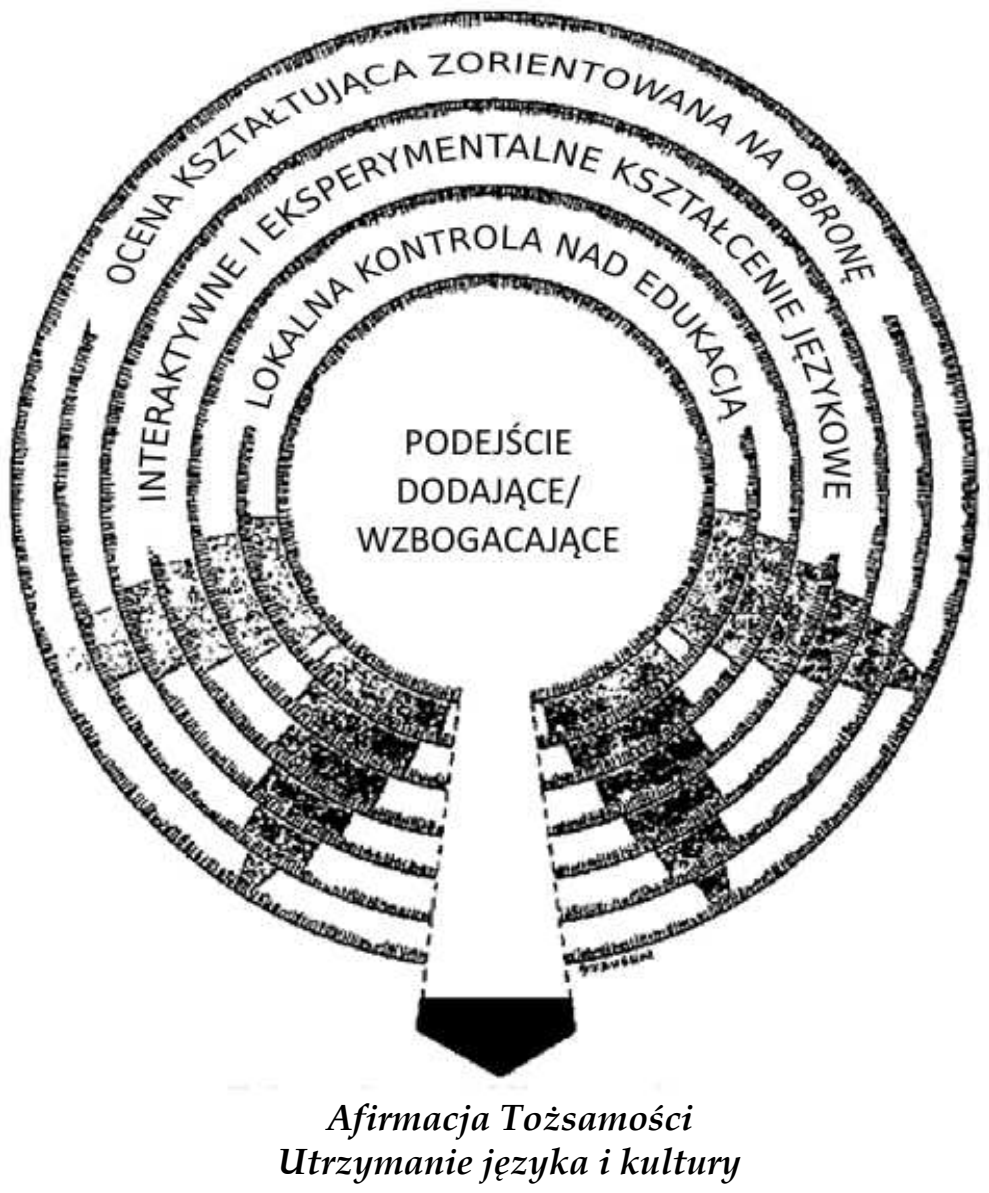

Ryc. 6. Pedagogiczne strategie wzmacniania tubylczych języków i kultur w Instytucie Rozwoju Języków Amerykańskich Indian

(Źródło: T.L. McCarty, L.J. Watahomigie, A.Y. Yamamoto, O. Zepeda, School-Community-University Collaborations: The American Indian Language Development Institute, [w:] Teaching Indigenous Languages, red. J. Reyhner, Flagstaff 1997, s. 90)

${ }^{37}$ Por. adres internetowy: http://aildi.arizona.edu 
Pierwszy poziom dotyczy podejścia dodającego/wzbogacającego. Jego istotą jest wzbogacanie oraz rozwijanie zasobów lingwistycznych i kulturowych, które dzieci przynoszą do szkoły. Drugi poziom odnosi się do lokalnej kontroli nad edukacją. Oznacza to przejęcie władzy decyzyjnej i kontroli nad programem kształcenia. Takie podejście implikuje tworzenie podstaw środowiska kształcenia dla dzieci opartego na wiedzy i doświadczeniu kulturowym oraz dziedzictwie lingwistycznym danej społeczności. Poziom trzeci odnosi się bezpośrednio do użycia języka tubylczego w edukacji. Zastosowanie języka tubylczego powinno zmierzać do motywowania młodych ludzi do używania języka własnej społeczności w sposób naturalny (w codziennym życiu) oraz kreatywny (co ma na celu dociekanie, krytykę i rozwój własnej wiedzy przez uczniów). Wreszcie, czwarty poziom powiązany jest z rozwiązaniami wzmacniającymi oraz kształtującymi rzeczywiste kompetencje językowe i kulturowe. Istotą jest podejście holistyczne, pozwalające dzieciom $\mathrm{w}$ większym stopniu w sposób autentyczny manifestować własne sposoby bilingwalnego rozwoju, niż tworzyć etykiety "braków” i sposoby „działań naprawczych”38.

Podsumowując, można stwierdzić, że w wielu krajach zamieszkiwanych przez tubylcze mniejszości etniczne rozwijane są modele edukacji tubylczej - służące lokalnym plemiennym społecznościom. Ich celem jest - podobnie jak w przypadku modeli i programów opisywanych powyżej - integracja tubylczej wiedzy w ramach obowiązującego kanonu szkolnego, ale przede wszystkich ochrona i rewitalizacja rdzennych kultur, które jeszcze kilka dekad wcześniej traktowane były jako element zagrażający kulturze dominującej. Ich reprezentanci z tego właśnie powodu byli dyskryminowani i funkcjonowali na marginesie kulturowym i społecznym.

Współcześnie społeczności tubylcze podejmują coraz to nowe próby ponownego określenia swej tożsamości oraz podtrzymania dziedzictwa kulturowego. Tendencję rewitalizacji kultury mniejszości etnicznych i narodowych można dostrzec nawet $\mathrm{w}$ krajach, gdzie polityka asymilacyjna zdała się odnieść sukces. Praktycznym wymiarem tych tendencji jest chęć edukowania młodego pokolenia w tradycjach, kulturze i języku danej mniejszości. Reprezentanci tubylczych mniejszości najczęściej dążą do uzyskania możliwości konstruowania programów kształcenia, zastosowania tubylczego języka jako pierwszego w edukacji szkolnej, jak również uzyskania wpływu na zarządzanie oświatą. Instytucjonalna edukacja stanowi bowiem dla nich obecnie jedyną realną szansę na zachowanie oraz rozwój własnego dorobku

38 T.L. McCarty, L.J. Watahomigie, A.Y. Yamamoto, O. Zepeda, School-CommunityUniversity Collaborations: The American Indian Language Development Institute, [w:] Teaching Indigenous Languages, red. J. Reyhner, Flagstaff 1997, s. 90. 
kulturowego i lingwistycznego, który był tworzony i przekazywany ustnie od tysięcy lat.

\section{BIBLIOGRAFIA}

Alaska Native Knowledge Network, adres internetowy: http:/ / www.ankn.uaf.edu/

Barnhardt R., Introduction, [w:] Sharing Our Pathways. Native Perspectives on Education in Alaska, red. R. Barnhardt, A.O. Kawagley, Fairbanks 2011.

Barnhardt R., Kawagley A.O., Indigenous Knowledge Systems and Alaska Native Ways of Knowing, Anthropology and Education Quarterly, 2005, 36, 1.

Champagne D., Strauss J., Defining Indian Studies through Stories and Nation Building, [w:] Native American Studies in Higher Education. Models for Collaboration between Universities and Indigenous Nations, red. D. Champagne, J. Strauss, Walnut Creek 2002.

Collignon B., Knowing Places: The Inuinnait, Landscapes and the Environment, Edmonton 2006.

Csonka Y., Changing Inuit Historicities in West Greenland and Nunavut, History and Anthropology, 2005, 16, 3.

Green J., Cannon Fodder: Examining the Future of Native Studies, [w:] Pushing the Margins: Native and Northern Studies, red. J. Oakes, R. Riewe, M. Bennett, B. Chisholm, Winnipeg 2001.

Heber R.W., Models for Indigenous Education, [w:] Indigenous Education and International Academic Exchange, red. R.W. Heber, X. Peng, Winnipeg 2014.

http:/ / aildi.arizona.edu

Jennings M.L., Collier J.R., One University, Two Universes: Alaska Natives and the University of Alaska-Anchorage, [w:] Native American Studies in Higher Education. Models for Collaboration between Universities and Indigenous Nations, red. D. Champagne, J. Strauss, Walnut Creek 2002.

Kanu Y., Integrating Aboriginal Perspectives Into the School Curriculum: Purposes, Possibilities, and Challenges, Toronto 2011.

Keskitalo P., Määttä K., Uusiautti S., Sámi Education, Frankfurt 2013.

Krupnik I., Shifting Patterns, Lasting Partnerships. Inuit Knowledge and Academic Science in Arctic Cultural Research, [w:] 11th Inuit Studies Conference, red. C. Andreasen, K. Langgård, Nuuk 1998.

Lipka J., Introduction: A Framework for Understanding the Possibilities of a Yup'ik Teacher Group, [w:] Transforming the Culture of Schools. Yup'ik Eskimo Examples, red. J. Lipka, G.V. Mohatt, London 1998.

Manuelito K., The Role of Education in American Indian Self-Determination: Lessons from Ramah Navajo Community School, Anthropology and Education Quarterly, 2005, 36, 1.

McCarty T.L., Watahomigie L.J., Yamamoto A.Y., Zepeda O., School-CommunityUniversity Collaborations: The American Indian Language Development Institute, [w:] Teaching Indigenous Languages, red. J. Reyhner, Flagstaff 1997.

McGregor H.A., Inuit. Education and Schools in the Eastern Arctic, Vancouver 2010.

Nee-Benham M.K.P., Cooper J.E., Gathering Together to Travel to the Source: A Vision for a Language and Culture-Based Educational Model, [w:] Indigenous Educational Models for Contemporary Practice. In Our Mother's Voice, red. M.K.P. Nee-Benham, J.E. Cooper, Mahwah 2000. 
Riley K.A., Abu-Saad I., Hermes M., Big Change Question. Should Indigenous Minorities Have the Right to Have Their Own Education Systems, Without Reference to National Standards? Journal of Educational Change, 2005, 6, 2.

Stairs A., Beyond cultural inclusion. An Inuit example of indigenous educational development, [w:] Minority Education: From Shame to Struggle, red. T. Skutnabb-Kangas, J. Cummins, Philadelphia 1998.

Taylor D.M., Crago M.B., McAlpine L., Toward Full Empowerment in Native Education: Unanticipated Challenges, The Canadian Journal of Native Studies, 2001, 21, 1.

Tester F.J., Irniq P., Inuit Qaujimajatuqangit: Social History, Politics and the Practice of Resistance, Arctic, 2008, 61, suplement 1.

Thornton M., Aspects of the History of Aboriginal People in their Relationships with Colonial, National and Provincial Governments in Canada, [w:] Aboriginal People and Other Canadians. Shaping New Relationships, red. M. Thornton, R. Todd, Ottawa 2001.

Trzciński P., Konstruowanie wspótczesnej tubylczości - tubylczość jako ideologia i obiekt prawa, [w:] Pierwsze narody. Społeczności rdzenne i idea tubylczości we wspótczesnym świecie, red. J. Derlicki, W. Lipiński, Warszawa 2002.

Vlassova T.K., Arctic Residents' Observations and Human Impact Assessments in Understanding Environmental Changes in Boreal Forests: Russian Experience and Circumpolar Perspectives, Migration and Adaptation Strategies for Global Change, 2006, 11, 4.

Watt-Cloutier S., Honouring Our Past, Creating Our Future: Education in Northern and Remote Communities, [w:] Aboriginal Education. Fulfilling the Promise, red. M.B. Castellano, L. Davis, L. Lahache, Vancouver 2000. 